\title{
SjCRT, a recombinant Schistosoma japonicum calreticulin, induces maturation of dendritic cells and a Th1-polarized immune response in mice
}

\author{
Lizhen Ma', Dandan Li ${ }^{1,2}$, Chunxiu Yuan ${ }^{1,3}$, Xiangqian Zhang ${ }^{1}$, Na Ta ${ }^{1}$, Xiaochao Zhao ${ }^{1}$, Yumei Li ${ }^{1,2}$
} and Xingang Feng ${ }^{1 *}$

\begin{abstract}
Background: It is well known that immunization of radiation-attenuated (RA) schistosoma cercariae or schistosomula can induce high levels of protective immunity against schistosoma cercariae reinfection in many animals. Many studies have shown that the Th1 cellular immune response is crucial for the protective effect elicited by RA schistosomula. However, the molecular mechanism of this strong protective immunity remains unclear.

Methods: The expression profiles of Schistosoma japonicum calreticulin (SjCRT) in RA and normal schistosoma-derived cells were investigated by flow cytometry. The effect of recombinant SjCRT (rSjCRT) on mouse dendritic cells (DCs) was determined by FACS, ELISA and RT-PCR analysis. We also analyzed the effects of SjCRT on the activation of spleen cells from mice immunized with rSjCRT by detecting lymphocyte proliferation and the cytokine profiles of splenocytes.

Results: We found that the expression level of SjCRT in the cells from RA larvae was significantly higher than that in cells from normal schistosomula at early stages of development (day 4). The results of effect of rSjCRT on mouse DCs showed that rSjCRT could induce phenotypic and functional maturation of DCs, and SjCRT bound to the surface of DCs through the CD91 receptor and could be engulfed by DCs. The results of activation of splenocytes from mice immunized with rSjCRT also demonstrate that rSjCRT can effectively stimulate the proliferative response of splenic lymphocytes, elicit splenocytes from immunized mice to secrete high levels of IFN- $\gamma$, TNF- $a$ and IL-4, and activate CD4+ T cells to produce high levels of IFN- $\gamma$.

Conclusion: SjCRT is one of the immunostimulatory molecules released from RA schistosomula cells, might play a crucial role in conferring a Th1-polarized immune response induced by RA cercariae/schistosomula in mice, and is a candidate molecule responsible for the high levels of protective immunity induced by RA schistosomula.
\end{abstract}

Keywords: Calreticulin, Schistosoma japonicum, Dendritic cells, CD4+ T cells

\section{Background}

Schistosoma japonicum is a causative agent of "intestinal" and "hepatic" schistosomiasis and is still endemic in seven provinces of China [1]. In order to sustainably control schistosomiasis, there is an urgent need to develop prophylactic vaccines with high efficacy and safety.

\footnotetext{
*Correspondence: xingangf62@aliyun.com

${ }^{1}$ Shanghai Veterinary Research Institute, Chinese Academy of Agricultural Sciences, Key Laboratory of Animal Parasitology, Ministry of Agriculture of China, Shanghai 200241, China

Full list of author information is available at the end of the article
}

Previous studies have indicated that vaccination with radiation-attenuated (RA) larvae is highly effective in many experimental hosts. However, it is unfeasible to apply RA vaccines to hosts because they are either unsafe or unavailable due to the lack of resources of schistosome larvae. Therefore, researchers propose that a molecular vaccine against schistosomiasis might be developed according to the effective mechanisms of protective immunity induced by an $\mathrm{RA}$ vaccine $[2,3]$. Further analysis of the mechanisms of protective immunity showed that irradiated lung-stage schistosomula 
(LS) were inducers of protective immunity, and LS was also shown to be the principal target of immunity in challenged animals [3]. This protective immunity is characterized by Th1-type immune responses, and is mainly mediated by $\mathrm{CD} 4+\mathrm{T}$-helper (Th) cells. However, the schistosome-derived cells/molecules responsible for the strong protective effects in the RA model remain unclear.

The concept of immunogenic cell death (ICD) was proposed to describe cellular mechanisms of anticancer immune responses, and accumulating experimental data indicate that immunogenic features of ICD are mediated by so-called 'Damage-Associated Molecular Patterns' (DAMPs), such as heat-shock protein (HSP), calreticulin (CRT), high mobility group protein B1 (HMGB1) and ATP [4]. Most of these molecules are intracellular molecules and have mainly nonimmunological functions within normal live cells, but they obtain immunostimulatory properties upon being exposed or released by damaged or dying cells [5]. DAMPs can exert their immunostimulatory effects when they are recognized by such receptors as membrane-bound/cytoplasmic pattern-recognition receptors, phagocytic/scavenger receptors and purinergic receptors. These DAMPs can mediate anticancer immunity because they can, together with cancer antigens, activate dendritic cells (DCs) and induce maturation of DCs, ultimately resulting in an adaptive immunity against cancer cells [4]. Among DAMPs, CRT has been more closely observed because Obeid et al. [6] showed that CRT exposure is a determining factor of immunogenicity of dying cancer cells. They found that anthracyclines can induce translocation of CRT to the surface of preapoptotic cells, and the immunogenicity of apoptotic cancerous cells can be suppressed by knockdown or blockade of CRT in mice. Therefore, immunogenic apoptosis associated with exposure of CRT on surface of the cell plays a key role in anticancer immunity.

In RA schistosome vaccine research, several studies have demonstrated differences in expression levels of immunogenic antigens between RA schistosomula and normal parasites. For example, Yang et al. [7] and Tian et al. [8] found that the expression level of S. japonicum heat-shock protein 70 (SjHSP70) derived from RA larvae is increased after RA treatment, and there is also evidence that the expression level of SjHSP70 on the cells from early RA schistosomula is significantly higher than that on cells from normal parasites [9]. Furthermore, in our preliminary study, a necrotic phenotype can be observed in in vitro cultured RA schistosomula. Therefore, we speculated that the immune responses induced by the RA schistosomula are qualitatively and/or quantitatively different from the immunity elicited by normal parasites. The increased immunogenicity of the RA larvae may be due to changes in the antigens exposed on the surface of the larvae and released into the extracellular milieu. These antigens include parasite-derived DAMPs, such as CRT, HSP70 and HMGB1. This situation might be similar to the aforementioned effector mechanism of anticancer immune responses induced by ICD. However, whether SjCRT is one of the main effectors of ICD or it might exert a key role in inducing high levels of innate and adaptive immune responses to an RA vaccine, remains to be identified. Thus in this study, we investigated the immunological function of SjCRT, including its expression profile in cells from RA and normal schistosomula, its recognition and engulfment by mouse dendritic cells, and the immunostimulatory effect of recombinant SjCRT on mouse DCs and splenic lymphocytes. We show that the expression level of SjCRT in early stage RA schistosomula was significantly higher than that in cells from normal parasites, and SjCRT could induce the maturation of DCs and facilitate a Th1-skewed immune response in mice.

\section{Methods}

\section{Protein, parasites and animals}

Recombinant SjCRT protein (rSjCRT) (GenBank: AAC00515) was obtained as described in Li et al. [10]. The limulus amebocyte lysate assay (LAL) was used to exclude LPS contamination of purified SjCRT protein $(<0.2 \mathrm{EU} / \mathrm{ml}$, which has been referred to as endotoxinfree). The concentration of protein was detected by BCA (Shanghai Shenggong). Six- to eight-week-old $\mathrm{BALB} / \mathrm{c}$ and $\mathrm{C} 57 \mathrm{BL} / 6$ mice were purchased from the Shanghai Experimental Animal Center, Chinese Academy of Sciences. Oncomelania hupensis infected with Schistosoma japonicum was obtained from the Jiangsu Institute of Parasitic Diseases (Wuxi, China).

\section{Generation of immature DCs}

Bone marrow cells were isolated from C57BL/6 mice. Then, $6 \times 10^{6}$ cells $/ \mathrm{ml}$ were cultured in complete RPMI supplemented with $2 \mathrm{ng} / \mathrm{ml}$ GM-CSF (Peprotech, Shanghai, China) and $1 \mathrm{ng} / \mathrm{ml}$ IL-4 (Peprotech) in 6well plates at $37^{\circ} \mathrm{C}, 5 \% \mathrm{CO}_{2}$ for 3 days. On the $3 \mathrm{rd}$ day, $2 \mathrm{ml}$ of the culture supernatant was carefully removed, and $3 \mathrm{ml}$ of fresh complete culture medium was added to each well and continued to culture for another 2 days at $37^{\circ} \mathrm{C}, 5 \% \mathrm{CO}_{2}$. On day 5 , the cells were collected, and immature DCs were isolated by using CD11c + MicroBeads (BD system, New Jersey, USA) according to the manufacturer's protocol. These bmDCs were found to be $>95 \%$ CD11c + as detected by flow cytometry (Beckman FC-500MPL, California, USA). 


\section{Preparation of polyclonal antibodies against SjCRT}

Six- to eight-week-old female BALB/c mice were housed in a specific-pathogen-free (SPF) environment. Twenty mice were divided into two groups. One group was injected subcutaneously with $100 \mu \mathrm{g}$ of $\mathrm{rSjCRT}$ emulsified in an equal volume of ISA206 adjuvant (Sigma-alorich, Shanghai, China), then mice were given two boosts with $50 \mu \mathrm{g} \mathrm{rSjCRT}$ emulsified with ISA206 adjuvant (Sigma) at 2 week intervals. At the same time, the other group was immunized with the same volume of PBS and ISA206 adjuvant as a control. Seven days after the third immunization, serum samples were collected from mice and stored at $-80^{\circ} \mathrm{C}$ until further analysis.

\section{Detection of the immunogenicity of SjCRT}

To test the immunogenicity of SjCRT, purified rSjCRT and the crude adult worm antigens were loaded into $12 \%$ SDS-PAGE gels, separated, transferred onto $0.22 \mu \mathrm{m}$ nitrocellulose membranes; the memebranes were blocked and washed as described in Duan et al. [9]. The membranes were then incubated in sera (diluted 1:100 in PBST) from mice immunized with $\mathrm{rSjCRT}$, infected with S. japonicum and from SPF mice respectively, at $37^{\circ} \mathrm{C}$ for 1 h. Next, membranes were washed three times with PBST and PBS respectively and incubated with 1:15,000diluted IRDye800CW (LI-COR, Nebraska, USA)-conjugated goat anti-mouse IgG (eBioscience) in the dark for $40 \mathrm{~min}$ at room temperature. The membranes were washed three times and photographed with the Odyssey Infrared Imaging System.

\section{Detection of the expression of SjCRT from RA and normal schistosomula cells}

The cells of RA and normal $S$. japonicum cercariae at different stages $(4,7,10$ or 14 days) were obtained as described in Duan et al. [9]. The schistosomula cells $\left(2 \times 10^{6}\right)$ from the RA and normal groups were collected and washed with pre-cooled PBS, fixed in $4 \%$ phosphate-buffered paraformaldehyde for $40 \mathrm{~min}$ on ice, and washed twice with pre-cooled PBS. The cells were suspended in PBS containing $0.2 \%$ Triton- $\times 100$ and $5 \%$ rabbit serum on ice for $10 \mathrm{~min}$ and then washed twice with precooled PBS. Cells from the two groups were incubated with anti-SjCRT mouse serum (diluted 1:200 in PBST) at $4{ }^{\circ} \mathrm{C}$ overnight. Meanwhile, negative mouse serum is diluted 1:200 in PBST as control group. After washing twice with PBST, the cells were incubated with 1:2000-diluted Alexa-Fluor ${ }^{\circ}$-488conjugated goat anti-mouse IgG $(\mathrm{H}+\mathrm{L})$ antibody in the dark for $40 \mathrm{~min}$. After washing the cells with PBST for three times, they were re-suspended in $400 \mu \mathrm{l}$ of pre-cooled PBS and analyzed by flow cytometry.

\section{Detection of the effect of $r S j C R T$ on immature DCs}

Immature 5-day DCs were obtained according to the above methods. The immature DCs $\left(2 \times 10^{6}\right.$ cells/each well of a 48-well plate) were stimulated with $50 \mu \mathrm{g} / \mathrm{ml}$ $\mathrm{rSjCRT}, 50 \mu \mathrm{PBS}$ and $50 \mathrm{ng} / \mathrm{ml}$ LPS at $37^{\circ} \mathrm{C}$ under $5 \%$ $\mathrm{CO}_{2}$ for $48 \mathrm{~h}$. Then, DCs were harvested and stained with PE-conjugated $\mathrm{mAbs}$ to $\mathrm{CD} 40$ and $\mathrm{PE} \mathrm{Cy7-}$ conjugated mAbs to CD86 (BD Systems, New Jersey, USA) at $4{ }^{\circ} \mathrm{C}$ in the dark for $30 \mathrm{~min}$, and these cells were washed twice and resuspended in $400 \mu \mathrm{l}$ of PBS and analyzed by flow cytometry. The supernatant was collected and IL-4, IL-10, TNF- $\alpha$ and IFN- $\gamma$ were detected using enzyme-linked immunosorbent assay (ELISA) kits (R\&D Systems, Minnesota, USA). The above stimulated DCs were harvested, and the expression of CCR7 and CXCR4 in DCs was assessed by RT-PCR and flow cytometric analysis. The primers used were 5'-CAT GGA CCC AGG TGT GCT TCT-3' and 5'-GTC AGT ATC ACC AGC CCG TT-3' for CCR7 and 5' -ATG GAA CCG ATC AGT GTG AGT-3' and 5'-TTG CCG ACT ATG CCA GTC AA-3' for CXCR4. The harvested DCs were stained with FITC-conjugated $\mathrm{mAbs}$ to CCR7 and PEconjugated mAbs to CXCR4 (BD Systems) at $4{ }^{\circ} \mathrm{C}$ in the dark for $30 \mathrm{~min}$, and these cells were washed twice and resuspended in $400 \mu \mathrm{l}$ of PBS and then analyzed by flow cytometry.

\section{Detection of polarization of CD4+ T cells by rSjCRT- pulsed mouse DCs}

Splenocyte suspensions were prepared from 6 to 8 week-old C57BL/6 mice according to the method as described by Duan et al. [9]. CD4+ T cells from the splenocyte suspensions were isolated using highgradient magnetic cell sorting (MACS, BD Systems) according to the manufacturer's protocol. DCs were pulsed with $50 \mu \mathrm{g} / \mathrm{ml} \mathrm{rSjCRT,} \mathrm{PBS} \mathrm{or} 50 \mathrm{ng} / \mathrm{ml}$ LPS at $37^{\circ} \mathrm{C}$ under $5 \% \mathrm{CO}_{2}$ for $48 \mathrm{~h}$, and these DCs were then harvested and washed twice with RPMI 1640. The aforementioned $\mathrm{CD} 4+\mathrm{T}$ cells were divided into 4 groups: Control group $\left(1 \times 10^{6} \mathrm{CD} 4+\mathrm{T}\right.$ cells and $1 \times$ $10^{5}$ DCs were co-cultured in the same well of a 48-well plate), ConA group $\left(1 \times 10^{6} \mathrm{CD} 4+\mathrm{T}\right.$ cells plus $5 \mu \mathrm{g}$ ConA), LPS group $\left(1 \times 10^{6} \mathrm{CD} 4+\mathrm{T}\right.$ cells and $1 \times 10^{5}$ DCs pulsed with LPS $)$ and SjCRT group $\left(1 \times 10^{6}\right.$ CD4+ $\mathrm{T}$ cells and $1 \times 10^{5} \mathrm{DCs}$ stimulated with $\mathrm{rSjCRT}$ ). These 4 groups were incubated in the dark at $37^{\circ} \mathrm{C}$ under $5 \%$ $\mathrm{CO}_{2}$ for 7 days. Six hours before the cells were harvested, PMA $(0.5 \mu \mathrm{g} / \mathrm{ml})$, ionomycin $(1 \mu \mathrm{g} / \mathrm{ml})$ and monensin $(3.5 \mu \mathrm{g} / \mathrm{ml})$ were added to each well. After being washed twice with cell staining buffer (CSB), the cells were stained in $200 \mu \mathrm{l}$ of CSB containing $2 \mu \mathrm{l}$ of $\mathrm{PE}-\mathrm{Cy} 5$-conjugated rat anti-mouse $\mathrm{CD} 4$ antibody at $4^{\circ}$ $\mathrm{C}$ in the dark for $30 \mathrm{~min}$. After washing twice with $\mathrm{CSB}$, the cells were incubated in $800 \mu \mathrm{l}$ of $4 \%$ 
paraformaldehyde on ice in the dark for $15 \mathrm{~min}$. The cells were then washed twice with CSB, and resuspended with $100 \mu \mathrm{l} 1 \%$ Triton- $\times 100$ on ice in the dark for $20 \mathrm{~min}$. After washing again twice with CSB, the cells were stained with FITC-conjugated rat anti-mouse IFN- $\gamma$ antibody and PE-conjugated rat anti-mouse IL-4 antibody at $4{ }^{\circ} \mathrm{C}$ in the dark for $30 \mathrm{~min}$. Cells were harvested and analyzed with flow cytometry.

\section{Observation of engulfment of rSjCRT and detection of fluorescent rSjCRT binding with CD91}

rSjCRT was conjugated to fluorescein isolthiocyanate (FITC) using a FITC conjugation kit (Abcam, Shanghai, China). Immature 5-day DCs were incubated with $20 \mu \mathrm{g} / \mathrm{ml}$ FITC-SjCRT in PBS containing 1\% skim milk powder in the dark for $20 \mathrm{~min}$ at $4{ }^{\circ} \mathrm{C}$. These DCs were washed twice with pre-cooled PBS. The pellet was then resuspended in $50 \mu \mathrm{l}$ precooled PBS and the suspension was mounted onto a precooled glass slide and visualized by a confocal microscope. The competitive binding assay was performed as follows: immature 5-day DCs were divided into several groups, and incubated in $2 \%$ paraformaldehyde on ice for $10 \mathrm{~min}$. The cells were washed twice and incubated with $0 \mu \mathrm{g} / \mathrm{ml} \mathrm{rSjCRT,} 20 \mu \mathrm{g} / \mathrm{ml}$ $\mathrm{rSjCRT}, \quad 100 \mu \mathrm{g} / \mathrm{ml} \quad \mathrm{SjCRT}$ and $20 \mu \mathrm{g} / \mathrm{ml} \alpha 2-$ Macroglobulin (ligand of CD91) respectively at $4{ }^{\circ} \mathrm{C}$ for $30 \mathrm{~min}$ and then further incubated with $2 \mu \mathrm{l}$ of FITCSjCRT at $4{ }^{\circ} \mathrm{C}$ in the dark for $30 \mathrm{~min}$. The cells were washed twice and resuspended in $400 \mu \mathrm{l}$ of PBS and analyzed by flow cytometry.

\section{Lymphocyte proliferation and cytokine analysis of splenocytes in mice immunized with rSjCRT}

In order to perform the lymphocyte proliferation assay, three mice of each group were selected. Seven days after the final immunization as described above, spleens were removed from the mice using scissors and forceps. The spleens were washed with cold RPMI 1640 medium (HyClone) and single-cell suspensions were obtained by passing them through a cell strainer. The suspensions were centrifuged at $1800 \times \mathrm{rpm}$ for $5 \mathrm{~min}$ at $4{ }^{\circ} \mathrm{C}$. Removing the supernatant, the precipitation was incubated with $2 \mathrm{ml}$ of red blood cell lysis buffer (TIANGEN) for $2 \mathrm{~min}$ to lyse the erythrocytes, and the reaction was stopped by adding $8 \mathrm{ml}$ of RPMI 1640 medium (HyClone). After washing twice with RPMI 1640 medium, the cells were resuspended in RPMI 1640 medium supplemented with $10 \%$ BSA to a final density of $1 \times 10^{6}$ cells $/ \mathrm{ml}$. Then, $200 \mu \mathrm{l}$ of the resuspension was seeded into a 96-well plate containing $5 \mu \mathrm{g}$ of ConA or $1 \mu \mathrm{g}$ of $\mathrm{rSjCRT}$. As the control group, the cells from the PBS group containing the same volume of ConA or PBS. The cells were cultured at $37^{\circ} \mathrm{C}$ under $5 \% \mathrm{CO}_{2}$ in the dark for 72 h. After incubation for 68 h, $100 \mu$ l of the culture supernatants of each well were collected for cytokine assay. Then, $50 \mu \mathrm{l}$ of MTT $(5 \mathrm{mg} / \mathrm{ml})$ was added to each well, and the cells were incubated for another $6 \mathrm{~h}$. The plates were centrifuged at 1000× rpm for $10 \mathrm{~min}$. The supernatants were gently removed, $100 \mu \mathrm{l}$ of DMSO was added to each well, and plates were incubated at $37^{\circ} \mathrm{C}$ in the dark for $5 \mathrm{~min}$. The absorbance was analyzed at $570 \mathrm{~nm}$ by a microplate reader (Thermo Multiskan MK3, Waltham, Massachusetts, USA). The values of stimulation index (SI) were calculated as follows:

$$
\mathrm{SI}=\frac{\text { Experimental cells A value }- \text { control A value }}{\text { Black control cells A value }- \text { control A value }}
$$

The levels of IL-4, IL-10, TNF- $\alpha$ and IFN- $\gamma$ were detected using ELISA kits (R\&D Systems).

\section{Detection of the ratio of CD4+/CD8+ T cells from spleens in mice immunized with rSjCRT}

On day 10 after the final immunization, three mice from each group were euthanized to obtain the spleens. Spleen single-cell suspensions were collected as above. The cells were centrifuged at $1500 \times \mathrm{rpm}$ for $5 \mathrm{~min}$ at $4{ }^{\circ} \mathrm{C}$, the supernatant was removed and the pellet was resuspended in $200 \mu \mathrm{l}$ of CSB. Then, the cells were stained with $2 \mu \mathrm{l}$ of PE-Cy7-conjugated rat anti-mouse CD3 antibody, $2 \mu \mathrm{l}$ of PE-conjugated rat anti-mouse CD4 antibody and $2 \mu \mathrm{l}$ of PE-Cy5-conjugated rat anti-mouse $\mathrm{CD} 8$ at $4{ }^{\circ} \mathrm{C}$ in the dark for $30 \mathrm{~min}$. The cells were washed twice with cold PBS, and were resuspended in $400 \mu \mathrm{l}$ of cold PBS and analyzed by flow cytometry.

Intracellular cytokines assay of CD4+ T cells from spleens in mice immunized with rSjCRT

On day 10 after the final immunization described above, four mice from each group were euthanized to obtain the splenic lymphocytes. The cells were counted and cultured in 48 -well plates at $1 \times 10^{7}$ cells $/ \mathrm{ml}$. Then, $50 \mu \mathrm{g}$ of $\mathrm{rSjCRT}$ was added to cells from rSjCRT-immunized mice to restimulate the cells, and the same volume of PBS was added to cells from the PBS-treated mice as controls. When cultured for $68 \mathrm{~h}$, PMA $(0.5 \mu \mathrm{g} / \mathrm{ml})$, ionomycin $(1 \mu \mathrm{g} / \mathrm{ml})$ and monensin $(3.5 \mu \mathrm{g} / \mathrm{ml})$ were added to each well and incubated for another $6 \mathrm{~h}$. The cells were harvested and washed twice with CBS. Cells were then resuspended in $200 \mu \mathrm{l}$ of CBS and $2 \mu \mathrm{l}$ of PE-Cy5-conjugated rat anti-mouse CD4 antibody was added. The cells were incubated at $4{ }^{\circ} \mathrm{C}$ in the dark for $30 \mathrm{~min}$, washed twice with CBS and incubated in $800 \mu \mathrm{l} 4 \%$ paraformaldehyde on ice in the dark for $15 \mathrm{~min}$. The cells were washed twice with CBS and resuspended with $100 \mu \mathrm{l} 1 \%$ Triton- $\times 100$ on ice in the dark for $20 \mathrm{~min}$. After washing twice with CBS, the cells were incubated with FITC-conjugated rat 
anti-mouse IFN- $\gamma$, PE-conjugated rat anti-mouse IL-4 antibody at $4{ }^{\circ} \mathrm{C}$ in the dark for $30 \mathrm{~min}$. The cells were harvested, washed twice, and analyzed using a flow cytometry.

\section{Statistical analyses}

Statistical analyses were completed using GraphPad Prism 5 software. The Student's test for analysis of data from different groups and analysis of variance (ANOVA) was used to test the differences among groups. The flow cytometry results were analyzed by FlowJo. The results were considered significant at a $P$ - value of $<0.05$.

\section{Results \\ Expression of SjCRT and its identification by immunoblotting}

The full length SjCRT nucleotide sequence amplified from the $S$. japonicum cDNA is comprised of $1188 \mathrm{nu}-$ cleotides, has no signal peptides, and encodes a 396amino acid protein with a predicted molecular mass of approximately $55 \mathrm{kDa}$. We constructed a plasmid of pET-28a-SjCRT and obtained a recombinant SjCRT protein. The results of immunoblotting demonstrated that the recombinant protein can be recognized by the serum of mice infected with S. japonicum (Fig. 1, Lane 2), the antiserum from mice immunized with rSjCRT also reacted with a crude adult worm antigen of $55 \mathrm{kDa}$ (Fig. 1, Lane 4), suggesting that rSjCRT has good antigenicity and that sera against $\mathrm{rSjCRT}$ can be used to determine the expression profile of SjCRT in the cells from normal and RA schistosomula.

$100 \mathrm{kDa}$ -
$55 \mathrm{kDa}$ -
$45 \mathrm{kDa}$ -
$35 \mathrm{kDa}$ -
Fig. $\mathbf{1}$ Analysis of the reactogenicity, antigenicity and immunogenicity
of rSjCRT. Lane M: protein molecular weight marker; Lane 1: rSjCRT is
recognized by the negative serum of SPF mice; Lane 2: rSjCRT is
recognized by sera of mice infected with Schistosoma japonicum; Lane
3: Negative serum from SPF mice recognizes the crude worm antigen
of Schistosoma japonicum; Lane 4: rSjCRT antiserum recognizes the
crude adult worm antigen of Schistosoma japonicum

Expression profile of SjCRT in the cells from RA and normal schistosomula cultured in vitro at different time points

To investigate whether there are differences in the expression profiles of SjCRT between RA and normal schistosomula, SjCRT expression from RA and normal schistosomula at different points in time were detected by flow cytometry. The expression level (mean fluorescence intensity, MFI) of SjCRT from RA schistosomuladerived cells was significantly higher than that of normal larvae on day 4 (Fig. 2 a1, b1 b1: $t_{(3)}=4.571, P=0.014$ ) after treatment. Meanwhile, on days 7, 10 and 14 after treatment, the expression of SjCRT from RA schistosomula was significantly lower than that from normal parasites (Fig. 2 a2-4, b2-4 b2: $t_{(3)}=5.537, P=0.0311$; b3: $\left.t_{(3)}=9.415, P=0.0025 ; \mathrm{b} 4: t_{(3)}=6.629, P=0.0070\right)$. These data suggest that $\mathrm{SjCRT}$ has higher expression levels in cells from very early stages of RA schistosomula.

rSjCRT can be engulfed by DCs through CD91 and induce DC maturation

Previous studies have revealed that CRT can exert its effects on anticancer immunity because it can be engulfed by DCs and induce maturation of DCs [11]. Therefore, we hypothesized that SjCRT may have similar immunobiological properties in antischistosomes immunity induced by RA schistosomula. To this end, we first investigated whether SjCRT could be engulfed by DCs. As described in Methods, FITC-labeled rSjCRT (rSjCRT-FITC) was incubated with immature mouse bone marrow-derived DCs, and the cells were observed under laser confocal microscopy. The results showed that green fluorescence could be observed both on the surface of the cells at $4{ }^{\circ} \mathrm{C}$ (Fig. 3a) and in the cytoplasm at room temperature (Fig. 3b), indicating that rSjCRT-FITC could bind to the surface of DCs and be engulfed by DCs. According to previous studies [12], CD91 is a common receptor for heat shock proteins hsp70, hsp90, CRT and gp96. Therefore, we determined whether SjCRT is also taken up by DCs through CD91. We performed a competitive binding test by using unlabeled rSjCRT and $\alpha 2$-macroglobulin ( $\alpha 2-\mathrm{M}$, a known ligand for the CD91 receptor) to evaluate decreases in rSjCRT-FITC uptake by DCs. We found that $100 \mu \mathrm{g} / \mathrm{ml}$ SjCRT $\left(t_{(3)}=15.66, P=0.0041\right), 20 \mu \mathrm{g} / \mathrm{ml}$ $\operatorname{SjCRT}\left(t_{(3)}=4.038, P=0.0482\right)$ and $\alpha 2-\mathrm{M}\left(t_{(3)}=15.93\right.$, $P=0.0039)$ can significantly inhibit binding of $\mathrm{rSjCRT}$ FITC to DCs as shown in Fig. 3c, d, indicating that both $\mathrm{rSjCRT}$ and $\alpha 2-\mathrm{M}$ have a common receptor of CD91 on DCs.

Since rSjCRT protein can be taken up by DCs, we further asked whether it can elicit maturation of DCs. In our previous study, we had indicated that $\mathrm{rSjCRT}$ can upregulate the expression of CD80 and MHC-II on mouse bone marrow-derived DCs (mDCs). In the 
a1

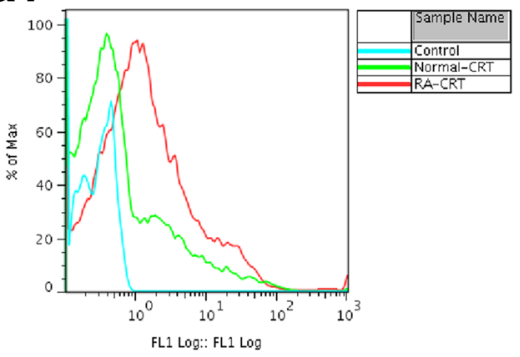

a2

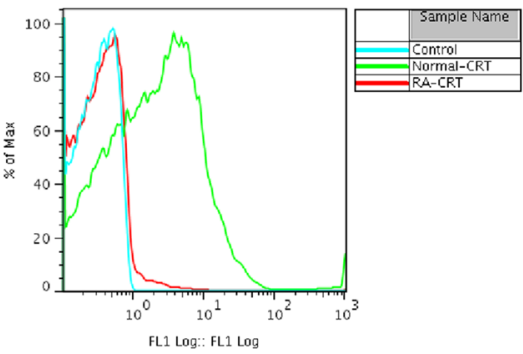

a3

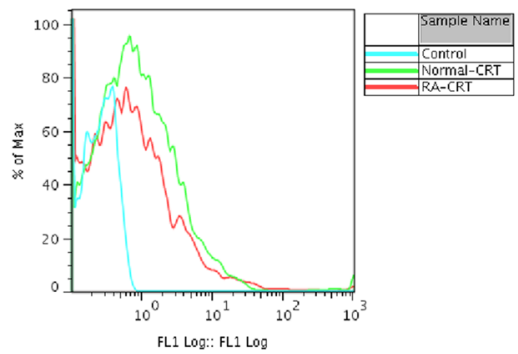

a4

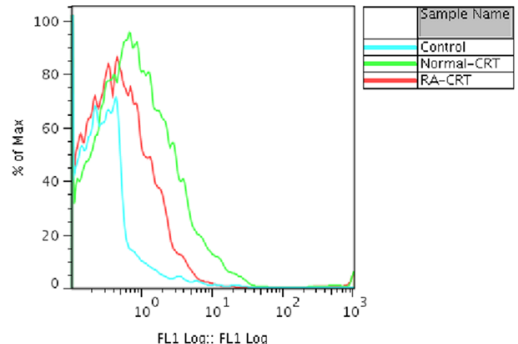

b1

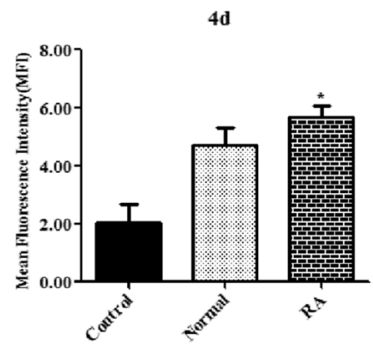

b2

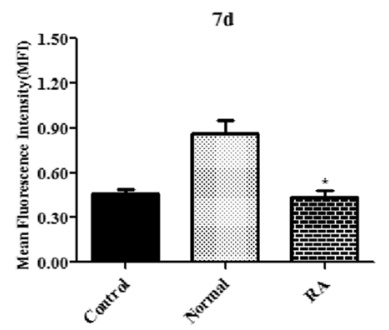

b3

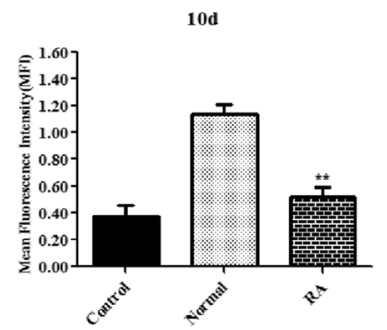

b4

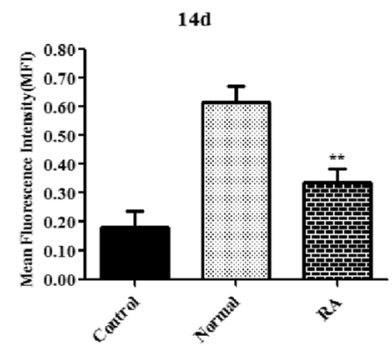

Fig. 2 SjCRT expression from RA and normal schistosomula at different stages. Cercariae were exposed or not exposed to a UV source (254 nm) at an intensity of $400 \mu \mathrm{W} / \mathrm{cm}^{2}$ for $1 \mathrm{~min}$ and the tails were detached before culture for 4, 7, 10 or 14 days. Schistosomula were digested into single cells and the cytomembrane was ruptured with $0.2 \%$ Triton- $\times 100$ on ice for 10 min. Then the cells were collected to determine the expression of SjCRT by flow cytometry. Data illustrating representative experiments and derived from triplicate experiments are shown as a graph (a1-a4) and mean fluorescence intensities (b1-b4) showing the means \pm SD from 4 samples, representative of two separate experiments. Statistically significant differences compared with the same stage of normal groups are shown as ${ }^{*} P<0.05$ or ${ }^{* *} P<0.01 \quad\left(\mathbf{b} 1: t_{(3)}=4.571, P=0.014\right.$; b2: $t_{(3)}=5.537, P=0.0311 ;$ b3: $\left.t_{(3)}=9.415, P=0.0025 ; \mathbf{b 4}: t_{(3)}=6.629, P=0.0070\right)$

present study, the expression of CD40 and CD86 on the surface of DCs was detected by flow cytometry. As shown in Fig. 4 a1-a2, b, rSjCRT can induce upregulation of CD40 $\left(t_{(3)}=11.93, P=0.0070\right)$ and CD86 expression on $\mathrm{mDCs}\left(t_{(3)}=3.486, P=0.0252\right)$, indicating that $\mathrm{rSjCRT}$ can elicit the phenotypic maturation of mDCs.
To determine whether rSjCRT can activate DCs and induce the functional maturation of DCs, the supernatants of 5-day DCs stimulated with $\mathrm{rSjCRT}$ were collected and analyzed for TNF- $\alpha$, IFN- $\gamma$, IL-4 and IL-10 secretion by ELISA. We found that DCs stimulated with rSjCRT secreted significantly higher amounts of TNF- $\alpha$ 

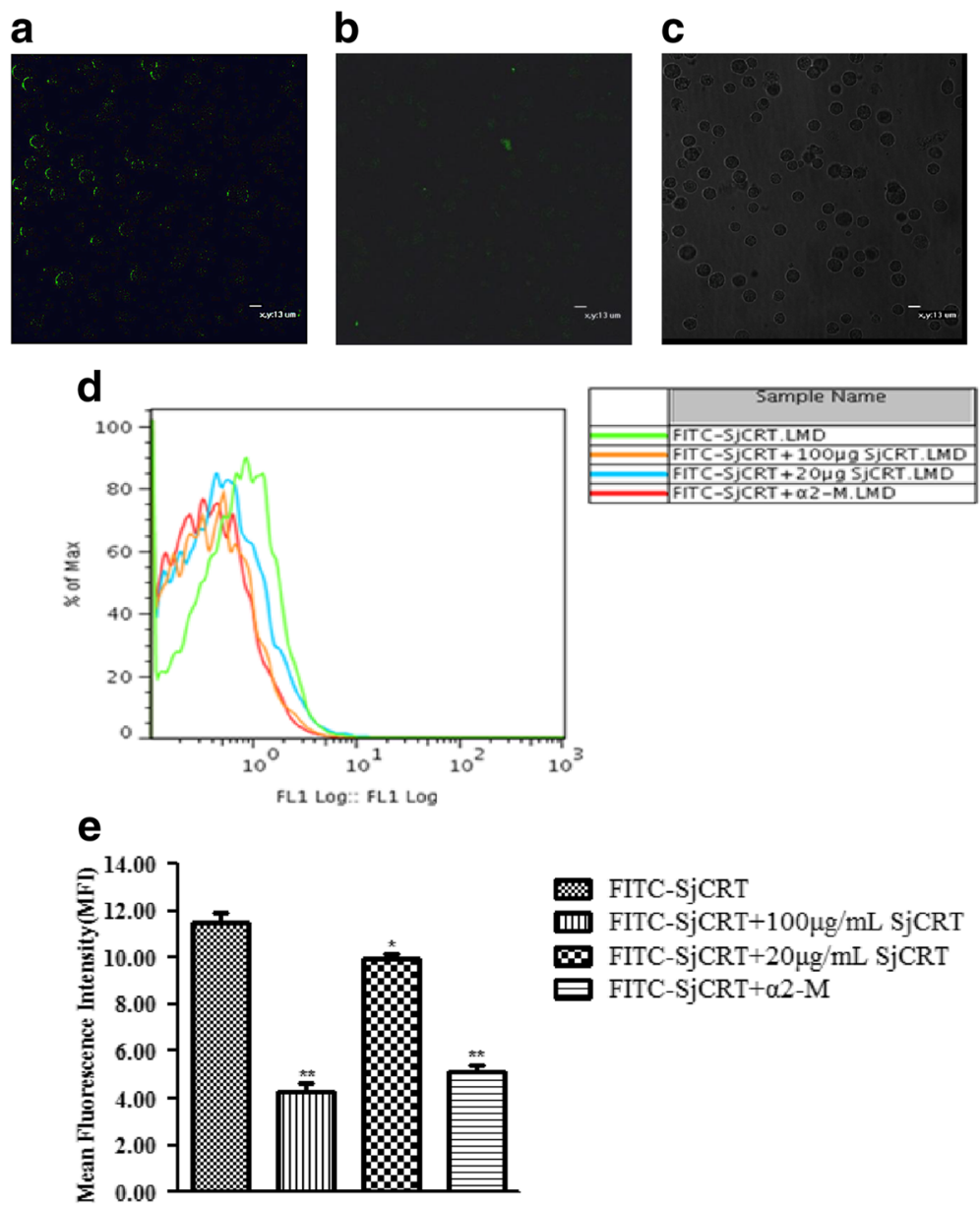

Fig. 3 FITC-SjCRT binds to DCs and can be engulfed by DCs through CD91. a FITC-SjCRT binds to the surface of DCs at $4{ }^{\circ} \mathrm{C}$. $\mathbf{b}$ FITC-SjCRT is endocytosed by DCs at room temperature. c Control of the same visual field. DCs fixed in paraformaldehyde were incubated with $20 \mu \mathrm{g} / \mathrm{ml}$ unlabeled SjCRT, $100 \mu \mathrm{g} / \mathrm{ml}$ unlabeled SjCRT and a2-M at $4{ }^{\circ} \mathrm{C}$ for $30 \mathrm{~min}$, and $2 \mu \mathrm{FITC}-\mathrm{SjCRT}\left(2 \mu \mathrm{g} / \mathrm{ml}\right.$ the final concentration) was then added at $4{ }^{\circ} \mathrm{C}$ for $20 \mathrm{~min}$. Then, cells were washed twice with precooled PBS, resuspended in $300 \mu \mathrm{l}$ precooled PBS and analyzed by flow cytometry. Data illustrating representative experiments derived from quadruplicate experiments (d) and mean fluorescence intensities $(\mathbf{e})$ are shown. Statistically significant differences compared with the control (FITC-SjCRT group) group are shown as ${ }^{*} P<0.05$ or ${ }^{* *} P<0.01\left(100 \mu \mathrm{g} / \mathrm{ml} \mathrm{SjCRT:} t_{(3)}=15.66, P=0.0041 ; 20 \mu \mathrm{g} / \mathrm{ml}\right.$ SjCRT: $t_{(3)}=4.038$, $\left.P=0.0482 ; \mathrm{a} 2-\mathrm{M} t_{(3)}=15.93, P=0.0039\right)$

$\left(t_{(5)}=65.63, P=0.0002\right), \operatorname{IFN}-\gamma\left(t_{(5)}=10.70, P=0.0017\right)$ and IL-4 $\left(t_{(5)}=13.45, P<0.0001\right)$ than those in the control group (Fig. 4 c1-c3). In contrast, rSjCRT could significantly suppress the secretion of IL-10 by DCs $\left(t_{(5)}=7.10, P=0.04\right)$ compared with the control group (Fig. 4 c4). The observed cytokine profile indicates that rSjCRT can induce functional maturation of DCs and suggests a Th1 bias, as TNF- $\alpha$ and IFN- $\gamma$ typically induce Th1 polarization.

It has been shown [13] that, under the condition of elevated levels of co-stimulatory molecules (CD40, CD80 and CD86) and increased levels of proinflammatory cytokines (TNF- $\alpha$, IL-6), DCs that undertake immunogenic phagocytosis can present antigens to $\mathrm{CD} 4+\mathrm{T}$ cells. These activated DCs can further activate Th1 cells, namely, IFN- $\gamma$-producing CD4+ T cells. To test this possibility, rSjCRT-pulsed mDCs were incubated with naive $\mathrm{CD} 4+\mathrm{T}$ cells, and production of the intracellular cytokines IFN- $\gamma$ and IL-4 by CD4+ T cells was then detected by flow cytometry (Fig. 5d). CD4+ T cells incubated with $\mathrm{rSjCRT}$-pulsed mDCs produced significantly higher levels of IFN- $\gamma\left(t_{(3)}=3.809, P=0.0318\right)$ than those incubated with control mDCs. Meanwhile, there was no significant difference in the levels of IL-4 $\left.t_{(3)}=2.693, \quad P=0.0742\right)$ between the aforementioned groups of $\mathrm{CD} 4+\mathrm{T}$ cells. These data indicate that $\mathrm{mDCs}$ pulsed with rSjCRT can facilitate differentiation of Th1 cells in vitro.

It was reported that the expression of chemokine receptors CCR7 and CXCR4 is induced during DC maturation [14, 15], and those chemokine receptors might direct the migration of DCs to the draining lymph nodes 
a1
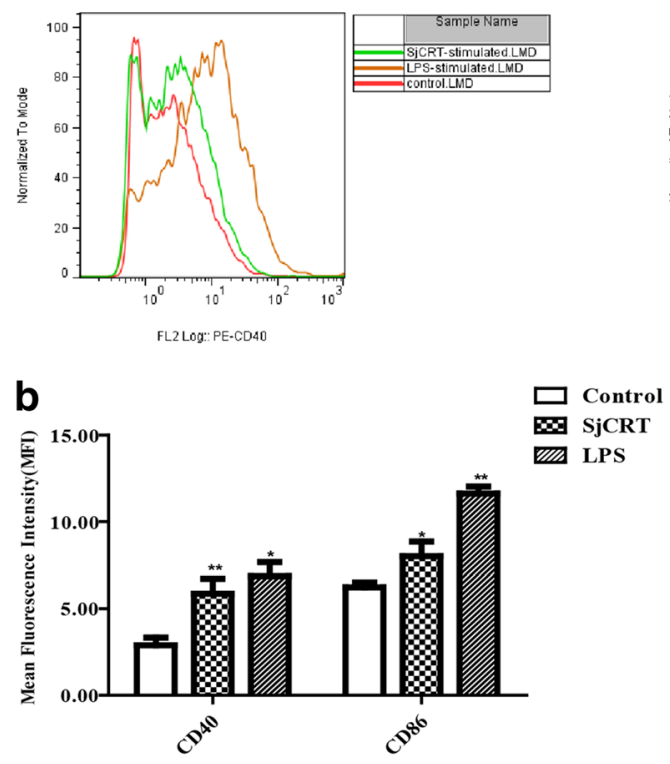

c2

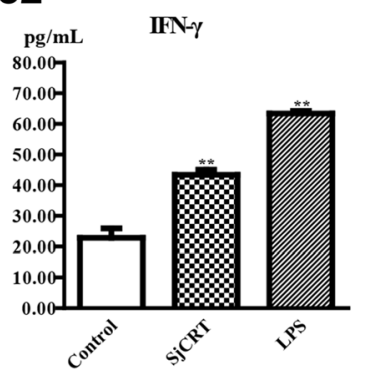

a2

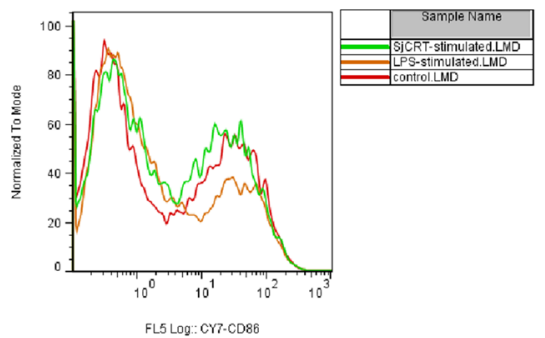

c1

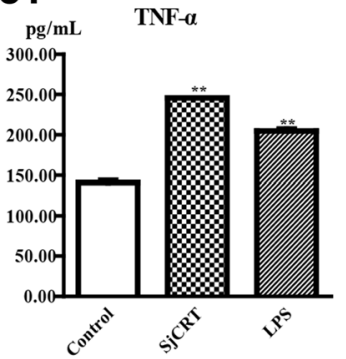

c4 c3

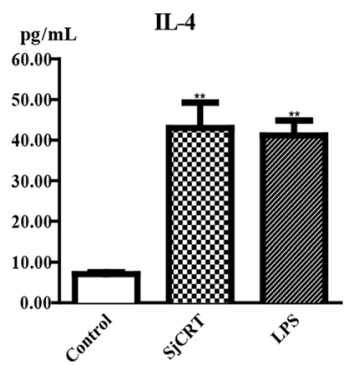

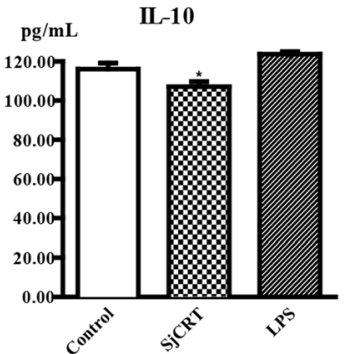

Fig. 4 Phenotypic and functional maturation of DCs induced by rSjCRT protein. DCs were treated with rSjCRT, LPS or PBS for 48 h, and cells were then collected for FACS analysis of CD40 and CD86 expression. CD40: LPS $t_{(3)}=5.506, P=0.0314 ;$ SjCRT: $t_{(3)}=11.93, P=0.0070 ;$ CD86: LPS $t_{(3)}=14.73$, $P=0.0046 ;$ SjCRT: $t_{(3)}=3.486, P=0.0252$. Supernatants were collected for ELISA analysis of IL-4, IL-10, TNF-a and IFN- $y$ secretion. PBS was the negative control, and LPS was the positive control. Data illustrating representative experiments derived from triplicate experiments (a1-a2) and mean fluorescence intensities (b) are shown. The production of cytokines is shown (c1-c4) TNF-a: LPS $t_{(5)}=29.13, P=0.0012, \mathrm{SjCRT}: t_{(5)}=65.63, P=0.0002 ;$ IFN- $\gamma$ : LPS $t_{(5)}=25.48, P<0.0001$, SjCRT $t_{(5)}=10.70, P=0.0017 ;$ IL-4: LPS $t_{(5)}=23.78, P<0.0001$, SjCRT $t_{(5)}=13.45, P=0.0001 ;$ IL-10: LPS $t_{(5)}=3.472 P=0.0403$, SjCRT $t_{(5)}=3.294, P=0.0460$. Statistically significant differences compared with the negative control group are shown as * $P<0.05$ or $* * P<0.01$

(LNs). Therefore, we assayed the expression levels of CCR7 and CXCR4 in DCs stimulated with rSjCRT using RT-PCR and flow cytometric analysis. We found that, after exposure to rSjCRT and LPS stimuli, DCs can upregulate expression of CCR7 and CXCR4 (Fig. 5 a1-a2; b1-b2; c1-c2), further suggesting that rSjCRT can induce functional maturation of DCs.

\section{rSjCRT promotes lymphocyte proliferation and induces} a Th1-biased immune response in mice immunized with rSjCRT

It has been shown in the RA vaccine mouse model that attenuated larvae stimulate proliferation of antigenspecific Th1 lymphocytes in the skin-draining lymph nodes. These CD4+ T cells can be recruited to the pulmonary parenchyma via the circulation and they provide the lungs with an immune micro-environment against a challenge with normal larvae $[16,17]$. The production of IFN- $\gamma$ and TNF- $\alpha$ by these cells is essential for cellmediated protective immunity [18]. Therefore, we speculated that SjCRT could also induce a predominantly Th1 immune response in the mouse spleen. To test this hypothesis, we first detected the proliferation of splenic lymphocytes from sensitized mice in response to rSjCRT re-stimulation using the MTT method and found that the values of stimulation index in splenic lymphocytes in rSjCRT-stimulated and ConA groups were significantly higher than that in the PBS control group (Fig. 6a) (SjCRT: $t_{(3)}=20.44, P=0.0003$; ConA: $\left.t_{(3)}=6.888, P=0.0063\right)$. This indicated that SjCRT can enhance lymphocyte proliferation in the spleen from mice immunized with $\mathrm{rSjCRT}$, and SjCRT-specific recall response might be elicited by $\mathrm{rSjCRT}$ re-stimulation. Then, we investigated the profiles of cytokines secreted 


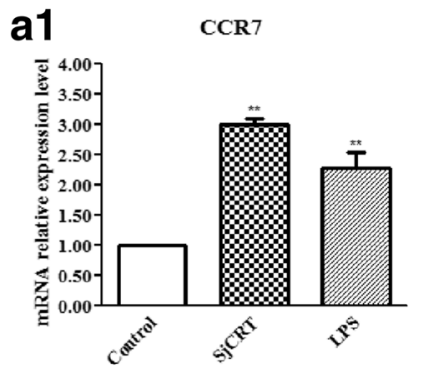

b1
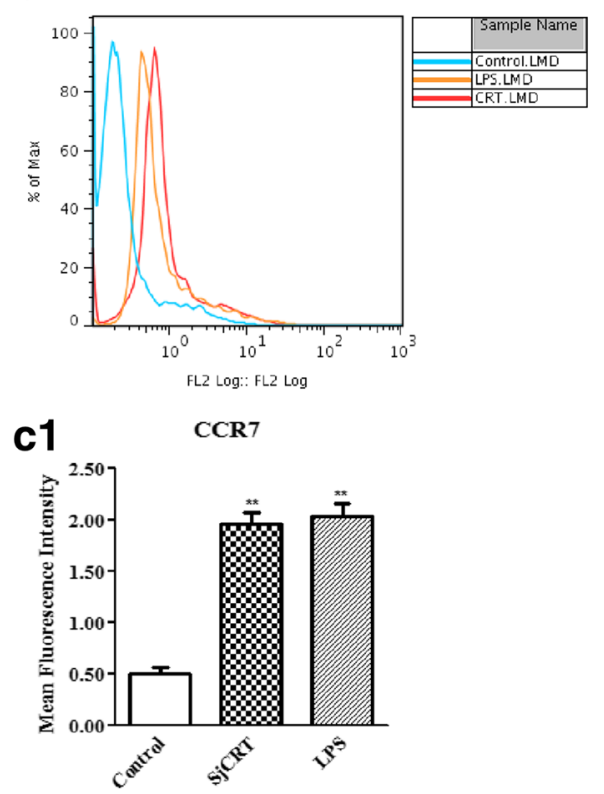

d

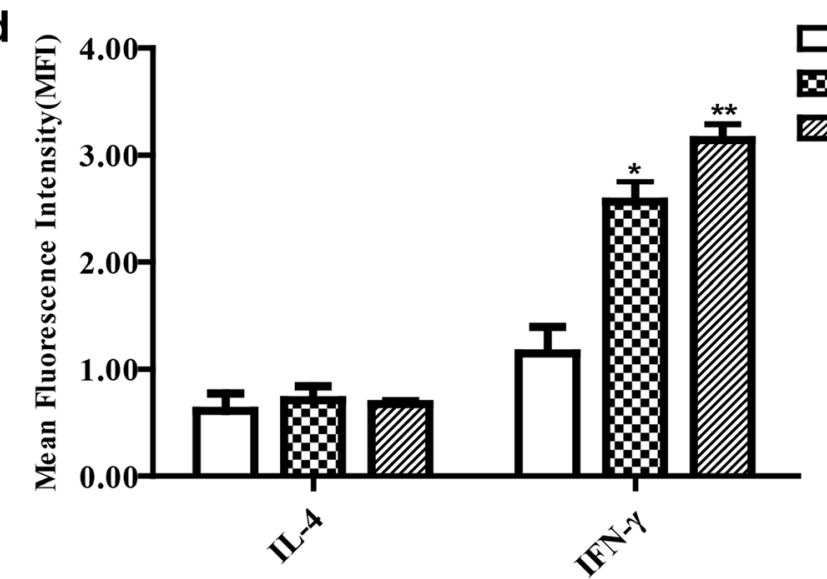

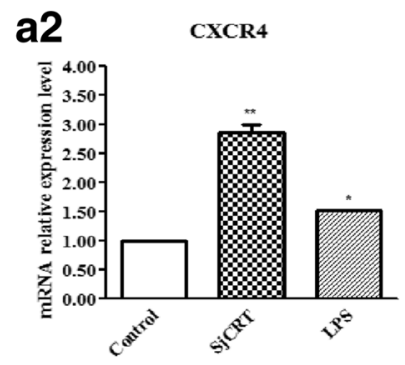

b2

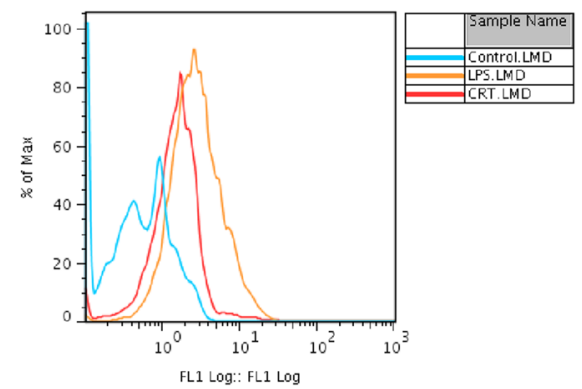

c2

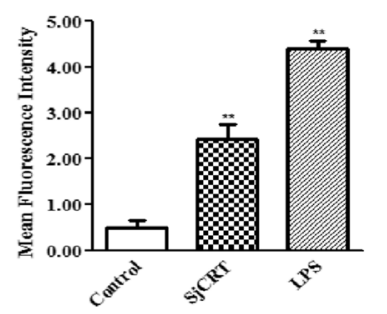

Fig. 5 SjCRT stimulates DCs to express the chemokine receptors CCR7 and CXCR4 and promotes CD4 ${ }^{+} T$ cells to secrete Th1-type cytokines. DCs were stimulated with rSjCRT, LPS or PBS for $48 \mathrm{~h}$. Cells were then harvested for analysis of CCR7 and CXCR4 expression by quantitative RT-PCR (a1-a2) CCR7: LPS $t_{(4)}=18.70, P=0.0079$, SjCRT $t_{(4)}=37.52, P=0.0007 ;$ CXCR4: LPS $t_{(4)}=8.30, P=0.02$, SjCRT $t_{(4)}=23.05, P=0.0019 ;$ and FACS (b1-b2, c1-c2) CCR7: LPS $t_{(3)}=14.54 P=0.0047$, SjCRT $t_{(3)}=14.39, P=0.0048 ; C X C R 4:$ LPS $t_{(3)}=111.7, P<0.0001$, SjCRT $t_{(3)}=9.931 P=0.0100$. Immature 5-day DCs were stimulated with $50 \mu \mathrm{g} / \mathrm{ml} \mathrm{SjCRT,} 50 \mu \mathrm{l} \mathrm{PBS}$ or $50 \mathrm{ng} / \mathrm{ml}$ LPS at $37^{\circ} \mathrm{C}$ under $5 \% \mathrm{CO}_{2}$ for $48 \mathrm{~h}$. The PBS group was used as the negative control, and the LPS group was the positive control. Isolated $\mathrm{CD}^{+} \mathrm{T}$ cells from the splenocytes were incubated with different groups of DCs at $37^{\circ} \mathrm{C}$ under $5 \% \mathrm{CO}_{2}$ for 7 days. The production of intracellular cytokines IL-4 and IFN- $\gamma$ by CD4 ${ }^{+}$T cells was measured by FACS (d) IL-4: LPS $t_{(3)}=2.458, P=0.0394, \operatorname{SjCRT} t_{(3)}=2.693$, $P=0.0742$; IFN- $\gamma$ : LPS $t_{(4)}=10.90, P=0.0017$, SjCRT $t_{(3)}=3.809, P=0.0318$. Statistically significant differences compared with the negative control group are shown as ${ }^{*} P<0.05$ or ${ }^{*} P<0.01$ 

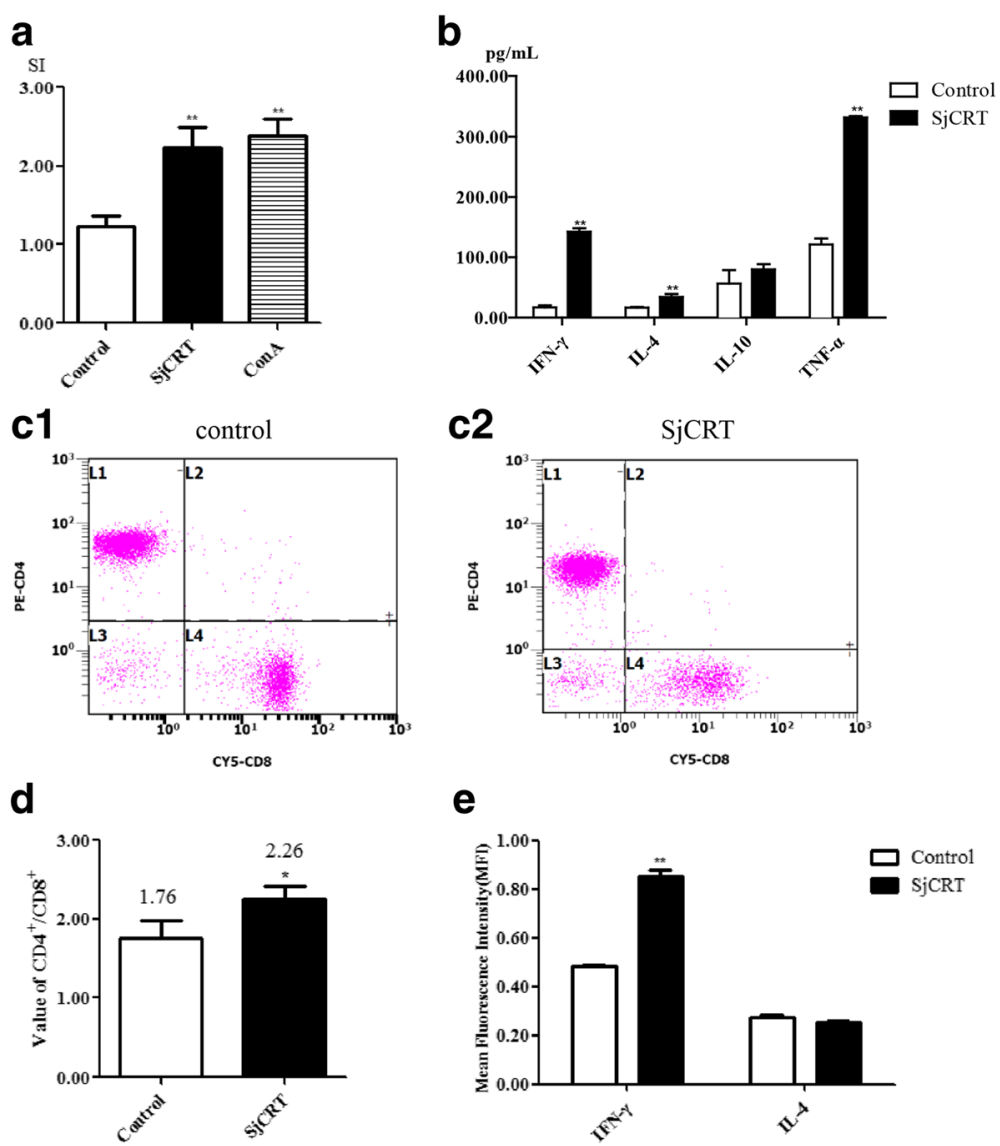

e

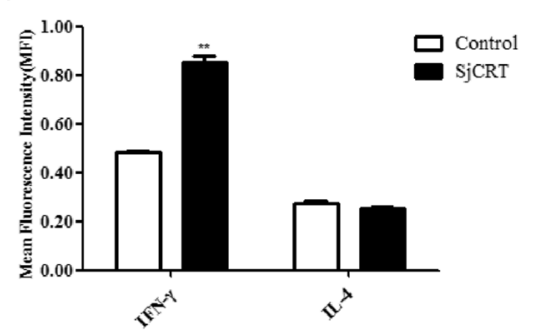

Fig. 6 Effect of rSjCRT on lymphocytes in mice. Splenocytes from immunized mice were re-stimulated with rSjCRT or PBS at $37{ }^{\circ} \mathrm{C}$ under $5 \% \mathrm{CO}_{2}$ for $72 \mathrm{~h}$. Splenocyte proliferation was assayed by MTT (a) SjCRT: $t_{(3)}=20.44, P=0.0003$; ConA: $t_{(3)}=6.888, P=0.0063$. The supernatants were collected, and the concentrations of IFN- $\gamma$, IL-4, IL-10 and TNF-a were measured by ELISA (b) IFN- $\gamma: t_{(3)}=29.63, P<0.0001 ; \mathrm{IL}-4: t_{(3)}=6.295, P=0.0081 ; I L-10$ : $t_{(3)}=1.510, P=0.2283$; TNF-a: $t_{(3)}=41.39, P<0.0001$. The re-stimulated cells were analyzed as the ratio of $C D 4^{+} / C D 8^{+} T$ cells by FACS. Data illustrating representative experiments derived from quadruplicate experiments are shown as a graph (c1-c2) and the ratio of $\mathrm{CD}^{+} / \mathrm{CD}^{+}(\mathbf{d})\left(t_{(4)}=3.422\right.$, $P=0.0267)$. The production of intracellular cytokines IL-4 and IFN- $\gamma$ by CD4+ T cells was measured by FACS (e) IFN- $-t_{(3)}=15.67, P=0.0006 ; \mathrm{IL}-4$ : $t_{(3)}=2.031, P=0.1352$. Statistically significant differences compared with the PBS group are shown as $* P<0.05$ or ${ }^{* *} P<0.01$

by these cells. Splenocytes from sensitized mice were incubated with $\mathrm{rSjCRT}$ at $37^{\circ} \mathrm{C}$ and $5 \% \mathrm{CO}_{2}$ for $68 \mathrm{~h}$, and the levels of cytokine production in the culture supernatant were determined by ELISA (Fig. 6b). The splenocytes of mice immunized with $\mathrm{rSjCRT}$ produced much higher levels of proinflammatory (TNF- $\alpha$ : $t_{(3)}=41.39, P<0.0001$ and IFN- $\gamma: t_{(3)}=29.63, P<0.0001$ ) and Th2-type (IL-4: $\left.t_{(3)}=6.295, P=0.0081\right)$ cytokines than the cells of the control mice, whereas there was no significant difference in the production of a regulatory cytokine IL-10 $\left(t_{(3)}=1.510\right.$, $P=0.2283$ ) between the SjCRT-stimulated and control groups, suggesting that a Th1-biased immune microenvironment can be elicited by rSjCRT re-stimulation in the spleen from mice immunized with rSjCRT. Furthermore, we asked whether $\mathrm{CD} 4+\mathrm{T}$ cells may also be involved in the above activity. To this end, we analyzed the ratio of $\mathrm{CD} 4+\mathrm{T} / \mathrm{CD} 8+\mathrm{T}$ cells in the spleens of mice either immunized with rSjCRT or PBS-vaccinated using FACS.
We found that the ratio value (equal to 2.26) of CD4+ T / CD8+ $\mathrm{T}$ cells from the splenocytes of rSjCRTimmunized mice was significantly higher than that (equal to 1.76) of CD4+ T / CD8+ T cells from control mice $\left(t_{(4)}=3.422, P=0.0267\right)$ (Fig. 6c1-c2, d), indicating that $\mathrm{CD} 4+\mathrm{T}$ cells are mobilized in the spleens from rSjCRT-immunized mice. Then, after splenocytes of rSjCRT/PBS-immunized mice were re-stimulated with $\mathrm{rSjCRT/PBS}$, we detected production of the intracellular cytokines IFN- $\gamma$ and IL- 4 by $\mathrm{CD} 4+\mathrm{T}$ cells from the above splenocytes using FACS. The results showed that CD4+ $\mathrm{T}$ cells from splenocytes of $\mathrm{rSjCRT}$-immunized mice produced higher levels of IFN- $\gamma$ than the cells from splenocytes of control (PBS-immunized) mice (Fig. 6e) $\left(t_{(3)}=15.67, P=0.0006\right)$. In contrast, the level of IL-4 produced by CD4+ T cells from splenocytes of rSjCRT-immunized mice did not differ significantly from the cells of control mice $\left.t_{(3)}=2.031, P=0.1352\right)$. 
These results indicated that IFN- $\gamma$-producing $\mathrm{CD} 4+\mathrm{T}$ cells or Th1 cells were activated by $\mathrm{rSjCRT}$ restimulation and may contribute to the generation of a Th1-biased immune microenvironment in the spleens of rSjCRT-immunized mice.

\section{Discussion}

The importance of calreticulin as an effector molecule of immunogenic cell death in radiation cancer therapy has been established in recent studies [4, 19]. In the present study, we concentrated on immunogenic properties of SjCRT from both RA schistosomula (RAS) and recombinant protein, and we provide preliminary evidence for the exposure of SjCRT on the surface of cells in early stage RA schistosomula and activation of immune cells (DC and lymphocytes) stimulated with $\mathrm{rSjCRT}$ protein in the mouse model. These findings suggest that SjCRT might be one of the main effectors of immunogenic cell death and may play an important role in protective immunity induced by the RA schistosomula vaccine.

The current consensus [3] is that a focal response around challenge larvae is cell-mediated in pulmonary parenchyma and this effector mechanism involves IFN$\gamma$-producing CD4+ $\mathrm{T}$ cells, and TNF- $\alpha$-mediated immune responses are required for this protective immunity. This suggests that a Th1 biased microenvironment is essential for immune responses in RA vaccine models. This type of immunity is similar to that of the immune response induced by intracellular protozoa [20], instead of a Th2-mediated protective immunity elicited by nematode helminths [21]. These proinflammatory Th1 responses are supposed to be elicited by RA schistosomula cells undergoing immunogenic cell death [22]. In fact, our preliminary studies demonstrated that different forms of cell death were observed by transmission electron microscopy (TEM) in cells from both normal and RA larvae. Thus, cells derived from RA schistosomula have been shown to have morphological features of necrotic cell death during the course of in vitro culture for 14 days, whereas normal larvae-derived cells have the characteristics of apoptotic cells (unpublished data). Therefore, we speculated that RAS-derived cells may have some properties of immunogenic cell death that is induced by certain agents (e.g. anthracyclines, irradiation and hypericin-based photodynamic therapy) in a tumor prophylactic vaccination model, in which dying cancer cells' exposure or release of several molecules (e.g. calreticulin, HSP70, HMGB1 and ATP) dictate tumor immunogenicity, and these DAMPs are able to activate various kinds of immune cells such as natural killer cells (NK), macrophages and DCs [5]. To validate this hypothesis, we investigated the expression profile of SjCRT in cells from RA and normal schistosomula cultured in vitro at different points of time, and we found that intracellular SjCRT is expressed at higher levels in early stage RA schistosomula, suggesting that the increase in the abundance of intracellular SjCRT might be correlated with the early SjCRT exposure on the surface of the plasma membrane. This deduction is also supported by our previous observation in which SjCRT was located near the cell membrane within cytoplasmic areas of RAS-derived cells on day 7 after UV irradiation of schistosoma larvae. In contrast, SjCRT in the normal larvae-derived cells is distributed throughout the whole cytoplasm (unpublished data). This finding demonstrated that RAS-derived cells translocate relatively more SjCRT into the cell membrane than normal larvaederived cells during early stages. As previously indicated [9], early-stage RAS-derived cells undergo a cellular stress response with characteristics of elevated SjHSP70 levels on the surface of the cells, and this response might inhibit cell apoptosis induced by UV-irradiation, causing necroptosis-like cell death of RA schistosomula. With extended culture time, the expression of SjCRT in cells from RA larvae was significantly lower than that from corresponding normal schistosomula. It is probable that damage of cells treated with UV irradiation is more severe than of normal cells cultured in vitro; this might lead to a breach of plasma membrane integrity and decrease the levels of cytoplasmic and membrane-bound $\mathrm{SjCRT}$. Therefore, in terms of exposure/release of SjCRT and SjHSP70 molecules, the form of cell death in RA schistosomula is different from that in normal larvae. Thus, a plausible explanation is that cells from normal schistosomula cultured in vitro may have more apoptotic properties, whereas cells from RA parasites may show more necroptotic features. These different forms of cell death lead to distinct types of immune responses. When these apoptotic cells are engulfed by dendritic cells they may bring about a tolerance in hosts, whereas necroptotic cells may elicit an immunogenic response [23, 24]. Whether it is truly the case remains to be determined experimentally.

As we have known, CRT as one of the 'eat me' signal molecules plays a crucial role in the clearance of dying cells [6]. Generally speaking, tolerogenic 'eat me' signals that interact with immature DCs might cause tolerogenic phagocytosis whereas immunogenic 'eat me' signals that interact with immature DCs might favor immunogenic phagocytosis. DCs that undergo tolerogenic phagocytosis are unable to attain functional maturation, whereas DCs that undergo immunogenic phagocytosis can exhibit phenotypic and functional maturation; namely, they can present antigens to CD4+ T cells under the condition of elevated levels of costimulatory molecules and proinflammatory cytokines [25]. Many studies have indicated that exposure and release of CRT could induce DC maturation, activation 
and related cytokine secretion [26]. Therefore, we speculated that SjCRT has similar functions. To this end, we first obtained recombinant SjCRT protein (rSjCRT), and we then investigated whether $\mathrm{rSjCRT}$ is able to elicit activation and maturation of mouse DCs. We found that rSjCRT indeed could elicit phenotypic and functional maturation of DCs, especially producing higher levels of proinflammatory cytokines (TNF- $\alpha$ and IFN- $\gamma$ ), indicating that SjCRT can mediate immunogenic phagocytosis by mouse DCs and might provide a microenvironment for CD4+ T-cell-mediated adaptive immunity induced by RA schistosomula vaccines. We also found that the aforementioned immunogenic phagocytosis might be mediated by CD91 on the surface of DCs. This is not unexpected, since CD91 was previously reported to be a common receptor of heat-shock/chaperone proteins (gp96, Hsp70, Hsp90 and CRT), and this receptor is responsible for the cross-presentation of HSP-chaperoned peptides, leading to priming of $\mathrm{T}$ cell responses, especially peptide-specific cytotoxic $\mathrm{T}$ lymphocyte response in anticancer immunity [12]. Furthermore, several recent studies have found that CD91 might be involved in mediating CD4+ $\mathrm{T}$ cell responses; CD91 may take part in Hsp70-facilitated activation of human antigen-specific CD4+ memory T cells [27], and CD91 may also serve as a signaling receptor for these immunogenic HSPs, resulting in the maturation of DCs, cytokine secretion and priming of T-helper (Th) cells [28]. These data suggest that CD91 may be both an endocytic receptor and a signaling receptor to be engaged upon activation of DCs and differentiation of CD4+ T cells. In this study, we also confirmed that mDCs pulsed with $\mathrm{rSjCRT}$ can polarize naive CD4+ T cells towards differentiation of Th1 cells in vitro. A plausible explanation is that CD91 on the surface of mouse DCs might bind to SjCRT, allowing for internalization of SjCRT, regulating cell signaling for DC activation and secretion of proinflammatory cytokines (TNF- $\alpha$ and IFN- $\gamma$ ). This cytokine pattern is likely to be able to direct $\mathrm{T}$ cell responses to a Th1 phenotype. However, the mechanism underlying this process remains to be further elucidated experimentally.

Previous studies have demonstrated that the prolonged residence of RA schistosomula in the skin-draining lymph nodes (SLN) stimulates intense proliferation of antigenspecific Th1 lymphocytes, and these CD4+ T cells with Th1 characteristics can be recruited to the pulmonary parenchyma via the circulation. They may provide the lungs with an immune micro-environment against a challenge with normal larvae, suggesting that aforementioned CD4+ Th1 cells are mainly generated in the SLN $[17,19]$. However, they are also likely to be generated in the spleens of mice vaccinated with attenuated larvae because very little parasite-released material may be present in this organ due to the death of cells from attenuated larvae. In fact, it was reported that a high level of IFN- $\gamma$ can be detected in the mouse spleen in response to soluble schistosomular protein following vaccination with attenuated larvae [17], suggesting that an antigen-specific Th1 immune response can be elicited in the spleen. In the present study, we found that $\mathrm{rSjCRT}$ can stimulate lymphocyte proliferation in the spleen of mice immunized with rSjCRT, and CD4+ T cells from splenocytes of rSjCRT-immunized mice produced much higher levels of IFN- $\gamma$. These data further support the notion that SjCRT can also induce Th1-biased immune responses in the mouse spleen. We believe the immune property of these memory IFN- $\gamma$-producing CD4+ T cells is similar to that of the cells generated in SLN, namely that these $\mathrm{CD} 4+\mathrm{T}$ cells might also be recruited to the lungs and provide an effector cell population that can be rapidly stimulated by the challenge parasites [17]. However, the role of SjCRT in protective immunity induced by RA schistosomula remains to be demonstrated in vivo.

\section{Conclusions}

Our data suggest that SjCRT can be exposed on the surface of cells in the early-stage RA schistosomula, and rSjCRT can activate mouse DCs in a CD91-dependent manner and induce a Th1-polarized immune response in mice. Therefore, SjCRT can be considered a main effector of immunogenic cell death and might play a role in conferring a Th1-polarized immune response induced by RA cercariae/schistosomula in mice.

\section{Abbreviations \\ APC: Antigen present cells; BSA: Bovine serum albumin; CCR7: C-C chemokine receptor type 7; ConA: Concanavalin A; CRT: Calreticulin; CXCR4: C-X-C chemokine receptor type 4; DAMPs: Damage-associated molecular patterns; DC: Dendritic cells; DMSO: Dimethyl sulfoxide; ELISA: Enzyme-linked immunosorbent assay; GM-CSF: Granulocyte-macrophage colony stimulating factor; HSP: Heat-shock protein; ICD: Immunogenic cell death; IFN: Interferon; IL: Interlukine; LPS: Lipopolysaccharide; mAbs: Monoclonal antibodies: MFI: Mean fluorescence intensity; MTT: 3-(4,5-dimethyl-2-thiazolyl)-2,5-diphenyl- 2-H-tetrazolium bromide; PMA: Phorbol-12-myristate-13-acetate; RA: Radiation- attenuated; Sj: Schistosoma japonicum; TNF: Tumor necrosis factor; a2-M: a2- macroglobulin}

\section{Acknowledgements}

Not applicable

\section{Funding \\ The materials and animals of this study were supported by the National Key Basic Research Program (973 program) of China (Grant No. 2015CB150303) and the Special Fund for Agroscientific Research in the Public Interest, China (Grant no. 201303037), the Fund on Sci \& Tech Innovation Program of the Chinese Academy of Agricultural Sciences. The publishing expenses of this study was supported by the National Key Basic Research Program (973 program) of China (Grant No. 2015CB150303).}

\section{Availability of data and materials}

The data supporting the conclusions of this article are included within the article. Raw data will be available upon request.

\section{Authors' contributions}

$X F$ and $C Y$ conceived and designed the experiments; LM, DL performed the experiments; $L M, D L, X Z, N T, X Z$ and $Y L$ participated in animal model and 
sample collection; LM wrote the manuscript; XF critically revised the manuscript. All authors read and approved the final manuscript.

\section{Ethics approval}

This study was approved by the Animal Ethics Committee of the Shanghai Veterinary Research Institute, Chinese Academy of Agricultural Sciences (Permit No. shvri-sh-0985). All mice were handled in strict accordance with good animal practice according to the Animal Ethics Procedures and Guidelines of the People's Republic of China.

\section{Consent for publication}

Not applicable

\section{Competing interests}

The authors declare that they have no competing interests.

\section{Publisher's Note}

Springer Nature remains neutral with regard to jurisdictional claims in published maps and institutional affiliations.

\section{Author details}

'Shanghai Veterinary Research Institute, Chinese Academy of Agricultural Sciences, Key Laboratory of Animal Parasitology, Ministry of Agriculture of China, Shanghai 200241, China. ${ }^{2}$ College of Life and Environmental Sciences, Shanghai Normal University, Shanghai 250014, China. Jiangsu Co-innovation Center for Prevention and Control of Important Animal Infectious Diseases and Zoonoses, Yangzhou, Jiangsu Province 225009, China.

Received: 17 August 2017 Accepted: 31 October 2017

Published online: 13 November 2017

\section{References}

1. Zhang $L$, Xu ZM, Qian YJ, Dang H, Lv S, Xu J, et al. Endemic status of schistosomiasis in People's Republic of China in 2015. Zhongguo Xue Xi Chong Bing Fang Zhi Za Zhi. 2016;28(6):611-7.

2. Wilson RA, Coulson PS. Immune effector mechanisms against schistosomiasis: looking for a chink in the parasite's armour. Trends Parasitol. 2009;25(9):423-31.

3. Bickle QD. Radiation-attenuated schistosome vaccination: a brief historical perspective. Parasitology. 2009;136(12):1621-32.

4. Vandenabeele P, Vandecasteele K, Bachert C, Krysko O, Krysko DV. Immunogenic apoptotic cell death and anticancer immunity. Adv Exp Med Biol. 2016:930:133-49.

5. Krysko DV, Garg AD, Kaczmarek A, Krysko O, Agostinis P, Vandenabeele P. Immunogenic cell death and DAMPs in cancer therapy. Nat Rev Cancer. 2012;12(12):860-75.

6. Obeid M, Tesniere A, Ghiringhelli F, Fimia GM, Apetoh L, Perfettini JL, et al. Calreticulin exposure dictates the immunogenicity of cancer cell death. Nat Med. 2007;13(1):54-61.

7. Yang LL, Lv ZY, Hu SM, He SJ, Li ZY, Zhang SM, et al. Schistosoma japonicum: proteomics analysis of differentially expressed proteins from ultraviolet attenuated cercariae compared to normal cercariae. Parasitol Res. 2009;105(1):237-48.

8. Tian F, Hou M, Chen L, Gao Y, Zhang X, Ji M, Wu G. Proteomic analysis of schistosomiasis japonica vaccine candidate antigens recognized by UVattenuated cercariae-immunized porcine serum IgG2. Parasitol Res. 2013; 112(8):2791-803

9. Duan MM, Xu RM, Yuan CX, Li YY, Liu Q, Cheng GF, et al. SjHSP70, a recombinant Schistosoma japonicum heat shock protein 70 , is immunostimulatory and induces protective immunity against cercarial challenge in mice. Parasitol Res. 2015;114(9):3415-29.

10. Li Y, Li YY, Xu RM, Yuan CX, Yang JM, Lin JJ, et al. Expression of Schistosoma japonicum calreticulin protein in sf9 insect cells and preliminary analysis of its role in the activation of dendritic cells. Chin J Animal Infect Dis. 2012; 20(4):45-51.

11. Eggleton P, Bremer E, Dudek E, Michalak M. Calreticulin, a therapeutic target? Expert Opin Ther Targets. 2016;20(9):1137-47.

12. Basu S, Binder RJ, Ramalingam T, Srivastava PK. CD91 is a common receptor for heat shock proteins gp96, hsp90, hsp70, and calreticulin. Immunity. 2001;14(3):303-13.
13. Dudek AM, Martin S, Garg AD, Agostinis P. Immature, semi-mature, and fully mature dendritic cells: toward a DC-cancer cells interface that augments anticancer immunity. Front Immunol. 2013;4:438.

14. Kabashima K, Shiraishi N, Sugita K, Mori T, Onoue A, Kobayashi M, et al. CXCL12-CXCR4 engagement is required for migration of cutaneous dendritic cells. Am J Pathol. 2007;171(4):1249-57.

15. Kabashima K, Sugita K, Shiraishi N, Tamamura H, Fujii N, Tokura Y. CXCR4 engagement promotes dendritic cell survival and maturation. Biochem Biophys Res Commun. 2007;361(4):1012-6.

16. Coulson PS, Wilson RA. Recruitment of lymphocytes to the lung through vaccination enhances the immunity of mice exposed to irradiated schistosomes. Infect Immun. 1997;65(1):42-8.

17. Mountford AP, Coulson PS, Pemberton RM, Smythies LE, Wilson RA. The generation of interferon-gamma-producing $T$ lymphocytes in skin-draining lymph nodes, and their recruitment to the lungs, is associated with protective immunity to Schistosoma mansoni. Immunology. 1992;75(2):250-6.

18. Street M, Coulson PS, Sadler C, Warnock $\sqcup$, McLaughlin D, Bluethmann $H$, et al. TNF is essential for the cell-mediated protective immunity induced by the radiation-attenuated schistosome vaccine. J Immunol. 1999;163(8):4489-94

19. Derer A, Deloch L, Rubner Y, Fietkau R, Frey B, Gaipl US. Radioimmunotherapy-induced immunogenic cancer cells as basis for induction of systemic anti-tumor immune responses - pre-clinical evidence and ongoing clinical applications. Front Immunol. 2015;6:505.

20. Reiner SL, Locksley RM. The regulation of immunity to Leishmania major. Annu Rev Immunol. 1995;13:151-77.

21. Finkelman FD, Shea-Donohue T, Goldhill J, Sullivan CA, Morris SC, Madden $K B$, et al. Cytokine regulation of host defense against parasitic gastrointestinal nematodes: lessons from studies with rodent models. Annu Rev Immunol. 1997;15:505-33.

22. Obeid M, Panaretakis $T$, Joza N, Tufi $R$, Tesniere $A$, van Endert $P$, et al. Calreticulin exposure is required for the immunogenicity of gamma-irradiation and UVC light-induced apoptosis. Cell Death Differ. 2007;14(10):1848-50.

23. Zhou F, Lauretti E, di Meco A, Ciric B, Gonnella P, Zhang GX, et al. Intravenous transfer of apoptotic cell-treated dendritic cells leads to immune tolerance by blocking Th17 cell activity. Immunobiology. 2013; 218(8):1069-76.

24. Golden EB, Frances D, Pellicciotta I, Demaria S, Helen Barcellos-Hoff M, Formenti SC. Radiation fosters dose-dependent and chemotherapy-induced immunogenic cell death. Oncoimmunology. 2014;3:e28518.

25. Garg AD, Romano E, Rufo N, Agostinis P. Immunogenic versus tolerogenic phagocytosis during anticancer therapy: mechanisms and clinical translation. Cell Death Differ. 2016;23(6):938-51.

26. Raghavan M, Wijeyesakere SJ, Peters LR, Del Cid N. Calreticulin in the immune system: ins and outs. Trends Immunol. 2013;34(1):13-21.

27. Fischer N, Haug M, Kwok WW, Kalbacher H, Wernet D, Dannecker GE, et al. Involvement of CD91 and scavenger receptors in Hsp70-facilitated activation of human antigen-specific CD4+ memory T cells. Eur J Immunol. 2010:40(4):986-97.

28. Pawaria S, Binder RJ. CD91-dependent programming of T-helper cell responses following heat shock protein immunization. Nat Commun. 2011;2:521.

\section{Submit your next manuscript to BioMed Central and we will help you at every step:}

- We accept pre-submission inquiries

- Our selector tool helps you to find the most relevant journal

- We provide round the clock customer support

- Convenient online submission

- Thorough peer review

- Inclusion in PubMed and all major indexing services

- Maximum visibility for your research

Submit your manuscript at www.biomedcentral.com/submit
BioMed Central 